\title{
JUURNAL.RU
}

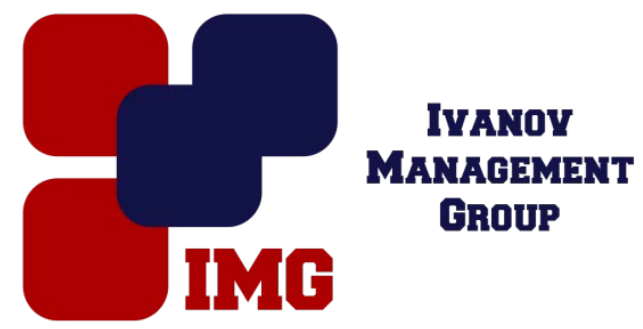

Мамедов Р.А., Антонов В.Ф. Институт сервиса, туризма и дизайна (филиал) федерального государственного автономного образовательного учреждения высшего образования «Северо-Кавказский федеральный университет» Пятигорск, Россия

doi: 10.18411/lj-31-10-2016-3-07

idsp 000001:lj-31-10-2016-3-07

\section{Характеристики терминологических единиц измерения распределенных атак на отказ в обслуживании канала}

Одним из основных способов обмена информацией является обработка данных и их компиляция в чёткой однозначной терминологии. Однако часто субъективность интерпретации получаемой информации регламентируется гранями классически устоявшейся терминологии, что значительно сужает спектр восприимчивости и накладывает некоторые сложности в восприятии и дальнейшем использовании существующих научно-технических трудов.

Таким образом, можно предположить, что ускорение процесса интегрирования инновационных механизмов в массы возможно посредством введения новых терминов и их популяризации. Одним из главных условий такого нововведения является ликвидация несогласованности и сокращения синонимизации новых терминов $\mathrm{c}$ классической терминологией в рассматриваемом аспекте.

В технических системах существует немалое количество совершенно новых направлений, которые только накапливают свою терминологическую базу, следовательно, иногда при обмене информацией по данной тематике возникает вопрос о дефиците терминологической базы.

Объектом исследования данной работы является класс атак распределенного отказа в обслуживании. Предметом исследования является терминологическая характеристика трафика. 
Целью статьи является повышение терминологической базы в области учета трафика при распределенной атаке на отказ в обслуживании канала.

Задачами статьи является: обоснование необходимости введения таких терминов как «ширина канала атаки» и «ширина канала клиента».

Актуальность рассматриваемой проблемы состоит в том, что для пояснения разницы между входящим нелегитимным трафиком и пропускными характеристиками канала используется термин «пропускная способность канала», что является неуместным: первоначально следует установить природу входящего нелегитимного трафика. Учитывая тот факт, что атака является распределенной, следует, что на конкретный момент времени на вход атакуемого канала попадает целый спектр сегментов, сгенерированных разными элементами сети.

Согласно теореме Шеннона - Хартли, пропускная способность канала обоначает верхнюю границу скорости передачи данных, которые возможно передать со средней скоростью через аналоговый канал связи, подверженный аддитивному белому гауссовскому шуму мощности, имеющему вид (1):

$$
\mathrm{C}=B * \log _{2}\left(1+\frac{S}{N}\right),
$$

где

C - пропускная способность канала бит/сек;

В - полоса пропускания канала, Гц;

$\mathrm{S}$ - полная мощность сигнала над полосой пропускания, Вт;

$\mathrm{N}$ - полная шумовая мощность сигнала над полосой пропускания, Вт;

$\mathrm{S} / \mathrm{N}$ - отношение мощности сигнала к шуму.

Таким образом, можно сделать вывод, что «пропускная способность канала атаки» является неуместным термином при использовании в коммуникативных вариациях аспектной проблемы распределенных атак на отказ в обслуживании канала. Следовательно, для введения нового целесообразного термина необходимо определить единицу измерения, под которой будет учитываться трафик канала атаки.

Наиболее адекватным решением в качестве единицы измерения будет являться сегмент одного из отправителей, участвующего в распределенной атаке. Таким образом, мощностью атаки будет являться сумма поступающих 
нелегитимных сегментов на канал атакуемой машины. Описать мощность канала атаки можно следующей формулой (2):

$$
\sum_{i=1}^{V} P_{t, i}
$$

где

$P$

$t, i$ - размер і-ого сегмента во времени t;

$V_{t}=\sum_{i=1}^{Z} 1$ при условии $P_{t, i} \leq n$,

где $\mathrm{z}$ - количество всех входящих сегментов зараженной сети в момент времени t; n - максимальный размер передаваемого сегмента.

Таким образом, распределенную атаку на отказ в обслуживании канала можно представить в виде схемы, отражающей транспортный уровень сетевой модели OSI, которая представлена на рисунке 1.

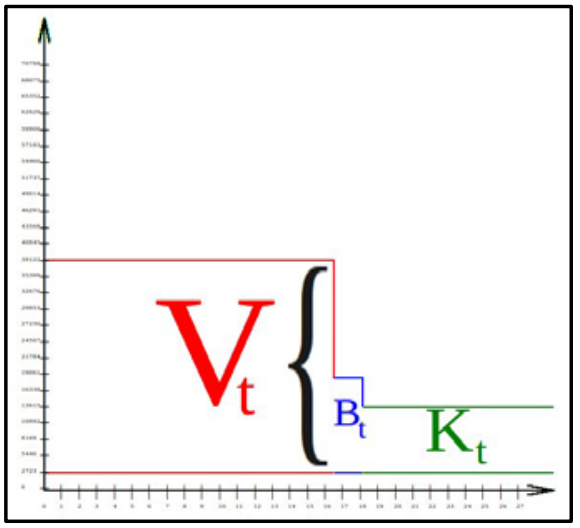

Рисунок 1 - Графическое представление распределенной атаки на отказ в обслуживании канала на транспортном уровне

Как видно из рисунка, задачей распределенной атаки является повышение нагрузки на канал атакуемой машины с целью его отказа в устойчивости. Таким образом, если рассматривать мощность распределенной атаки в виде суммы входящих нелегитимных сегментов $V_{t}$, стремящихся переполнить канал клиента, то $\mathrm{K}_{\mathrm{t}}$ можно обозначить термином «ширина канала клиента».

Под шириной канала атаки подразумевается количество сегментов зараженной сети, сосредоточенных в точке перехода в канал, подверженный атаке при условии того, что сегмент не должен превышать заданного размера n, 
где $\mathrm{B}_{\mathrm{t}^{-}}$размер буферного пространства, выделенного для временного хранения сегментов провайдером.

Учитывая тот факт, что для атаки был введен свой термин, использовать термин «пропускная способность канала клиента» будет не уместно по причине разнородности единиц измерения, так как это может привести к диссонансу при расчете разности для получения результата дефицита канала клиента (под клиентом подразумевается клиент провайдера, подверженный атаке).

Для решения данной проблемы следует ввести термин «ширина канала клиента», который описывается формулой (3).

$$
K_{j}=\sum_{i=1}^{m} 1
$$

$$
S p_{i} \leq n \wedge \sum_{i=1} S p_{i} \leq\left(S_{j}+B\right)
$$

где m - общее количество запросов;

$S$

j - пропускная способность канала;

n - максимальный размер передаваемого сегмента;

В - буферное пространство, выделяемое для временного хранения сегментов.

Для более четкого представления ширины канала клиента отобразим процесс функционирования данного аспекта в виде графической схемы, представленной на рисунке 2.

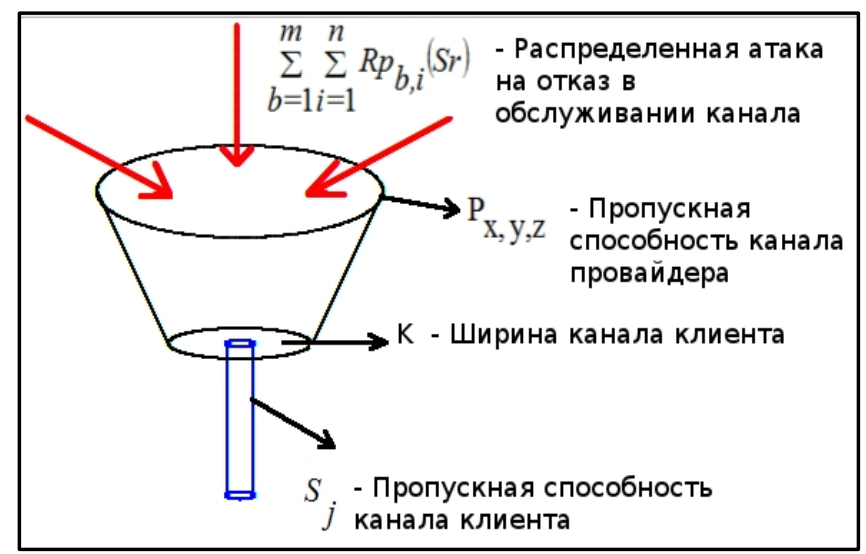

Рисунок 2 - Схема ширины канала клиента 
Дадим следующее определение: под шириной канала клиента подразумевается количество входящих сегментов $S p p_{i}$, ограниченных размером n, которые в сумме не могут превышать пропускную способность канала и буферного пространства.

Таким образом, мы рассматриваем две полярные процедуры распределенной атаки: «ширина канала атаки» и «ширина канала клиента» под одной единицей измерения. Такой подход дает возможность эффективно разграничивать приведенные термины. Кроме того, при этом представляется возможным использование в виде меры трафика не только количество сегментов, но также и в виде любой единицы измерения памяти, т.е. для получения размера проводимой атаки в мегабайтах, следует провести простую арифметическую операцию $\mathrm{V}_{\mathrm{t}} * \mathrm{n} / 1024^{2}$, что позволит работать с традиционными единицами измерения трафика.

\section{Заключение}

В ходе исследования терминологии, относящейся к сфере распределенных атак на отказ в обслуживании канала, была выявлена необходимость введения следующих терминов: «ширина канала атаки» и «ширина канала клиента». Это обусловлено дефицитом терминологических единиц в данном аспекте. Введение новых терминологических единиц позволит синхронизировать единицы измерения канала атаки и канала клиента. 


\section{Литература}

1. Лаборатория

Касперского:

https://securelist.ru/blog/issledovaniya/25740/stastika-ddos-atak-s-

ispolzovaniem-botnetov-v-pervom-kvartale-2015-goda (дата обращения 13.12.2015).

2. Мамедов Р.А. Анализ применения и последствия массированных атак распределенного отказа в обслуживании на сервер со среднестатистической мощностью // Научно-технический вестник Поволжья. - 2014. - № 3 - С. 150-157.

3. Мамедов Р.А. Системный анализ трафика провайдера на предмет выявления распределённой атаки на отказ обслуживания канала // Научный журнал Современная наука и инновации. - СтавропольПятигорск, 2014. - № 1 - С. 24-31. 